\title{
Fórum Social Mundial e a Saúde: por uma ética global da vida
}

The World Social Forum and Health: for the global ethics of life

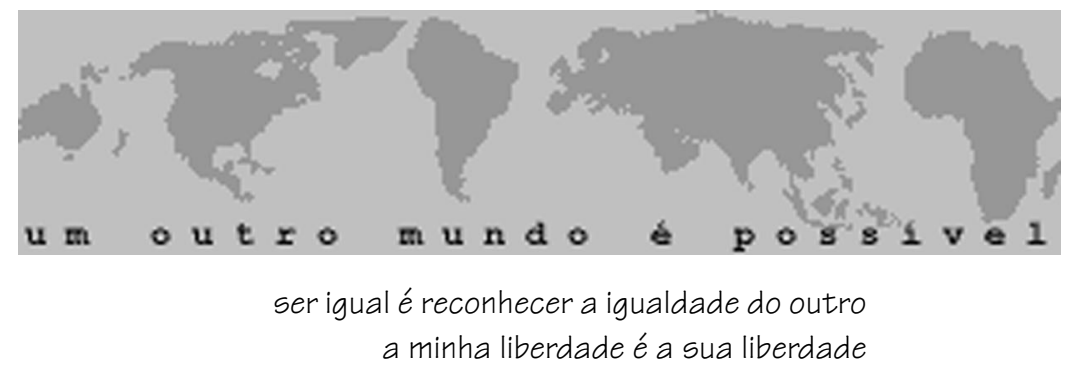

\section{Disputando imaginários e políticas}

Construir lugares em que grupos e indivíduos possam se posicionar sobre seus desejos e intenções, demarcados pelo terreno das relações sociais e implicados com a construção democrática de projetos e ações de saúde, é um dos principais caminhos que os movimentos sociais deste campo vêm apostando como forma de torná-lo profundamente envolvido com a produção de um modo de viver que não viole a potência de vida que há no mundo das coisas, das sociedades e das pessoas. Qualidades que não podem ser compartilhadas pelas relações sociais governadas por mecânicas instrumentais que a tudo transformam em recursos usáveis, como são as capitalísticas dirigidas. Estas têm sido demarcadas pela antiprodução da vida. Têm matado a cada dia a vitalidade naqueles mundos.

Produzir modos de viver coletivos que, ao construírem vida não gerem destruição, não só é possível como é um desafio a ser fabricado no dia a dia pelos coletivos sociais, que não querem se submeter aos processos capitalísticos. Hegemônicos, sem dúvida. Mas, isto exige lutas sem tréguas. Lutas pela possibilidade de ser imaginada. De ser desejada. De ser constituída. Produzida.

$E$ isto não é privilégio de um modo correto e único de viver, porém, é com certeza mais viável quanto mais múltiplos forem os modos de se inventar o viver, compatíveis com as muitas distintas maneiras de se poder criar e recriar os desejos e suas concretizações, com a aposta de que a minha vida é a sua vida, a minha liberdade é a sua liberdade, o meu direito é o seu direito. A minha igualdade é a sua igualdade. $\mathrm{Na}$ medida em que somos responsáveis pelo que construímos e estamos profundamente implicados com a produção da igualdade como a aceitação da singularidade do outro, com a defesa intransigente de que todos somos tão iguais, que devemos ser diferentes. Pensando assim, poderemos usufruir da crença em um futuro distinto do atual e mais rico para todos.

Mas, ledo engano de que isto seja tranqüilo de ser construído. Sua justeza não se traduz em facilidades; estas situações são duras de acontecer. Remam contra os processos exploradores da vitalidade das coisas, contra os interesses mesquinhos e de poucos, mas poderosos e dominantes. Contra a força do mercado. Contra a massacrante massificação de uma globalização capitalística que a todos se quer como iguais.

Exigem a produção permanente de coletivos autônomos, que não tenham medo de se publicizarem, de se submeterem às tensões tão necessárias dos encontros nos espaços públicos.

Exigem construir um Fórum atado à noção de que um outro futuro, diferente do predominante, é possível e que isto está vinculado às distintas maneiras de se criar e participar de processos coletivos de produção de novas subjetividades, implicadas com a defesa intransigente da vida individual e coletiva e a criação de situações interrogadoras para estes coletivos que Ihes permitam pensar sobre a realidade vivida, duvidar dela e intervir na busca de novos sentidos para si.

Com estes desejos, enormes, é que vejo a

${ }^{1}$ Departamento de Medicina Preventiva e Social da Faculdade de Ciências Médicas da Universidade Estadual de Campinas (UNICAMP) <emerhy@fcm.unicamp.br> 
importância de se refletir sobre as idéias fundamentais de um Fórum não espelhado simplesmente em Davos (o lugar do capital, do lucro, da exploração), mas seu fantasma. A possibilidade de sua negação imaginária, na ação.

O "pessoal da saúde" deve procurar se apropriar dessas idéias na perspectiva de permitir a expressão de sua multiplicidade interna no seu modo de buscar novos sentidos para sua prática, com a intenção de trocar vivências e experimentos, de produzir redes de produções de saberes, de solidariedades, de pautar eixos problematizadores, de se espalhar pelo mundo. Permitindo que suas conquistas e erros apareçam em espaços mais abrangentes, ampliando as possibilidades de compreensão.

Nesta direção, como exercício, proponho uma sistematização de alguns dos eixos problematizadores - apreendidos pela luta, no Brasil, por políticas e práticas de saúde totalmente voltadas à geração de mais vida -, que procuram se colocar em cada microprocesso institucional, tensionando-o como lugar de produção de novas subjetividades.

Construindo eixos problematizadores que favoreçam a busca de novos sentidos para as ações de saúde Colocar na parede, criar tensão produtiva. Por em dúvida o sentido perseguido. Apontar certos lugares implicados com uma aposta centrada na vida. Criar pautas de conversas em coletivos produtores de atos de saúde, em gestores de políticas e em operadores de serviços.

Estas são as apostas dos eixos problematizadores. Produzir interrogações que possam disparar processos coletivos de elaborações protagonizadoras. Que vêem o movimento do micro para o macro como o processo mais acumulativo e produtivo para as mudanças dos rumos em direção a um futuro diferente.

Neste sentido, os eixos apontados servem como idéias-apostas para serem usadas pelos coletivos, diante de muitas outras que os mesmos criarem, que podem operar a construção de novas maneiras de agir em saúde. Não são as únicas e nem as mais adequadas, necessariamente, diante das múltiplas realidades vivenciadas no território da saúde, mas funcionam como possibilidades de criar, no conjunto dos vários sujeitos interessados neste território, modos de um certo "olhar analítico" sobre o dia a dia das práticas de saúde, que abram para julgamento, compreensão e transformação, as várias maneiras de os trabalhadores coletivos operarem a construção dos sentidos de suas práticas, do ângulo da produção totalmente comprometida com a constituição de uma sociedade global mais implicada com a ética da vida.

Aposto que coletivos mais interrogadores, que colocam em dúvida seus microprocessos políticos, organizacionais e produtivos, tornam-se mais nítidos para si e para os outros, aumentando a chance de produzirem mecanismos mais solidários de agir. Tornam-se mais responsáveis e mais públicos. São mais democráticos. Possibilitam mexer no mundo aqui e agora de modo mais implicado.

\section{a vida de todos, e de cada um, é igualmente fundamental}

Considerar-se como território de saberes e práticas tecnológicas, produtoras de distintas maneiras de cuidar em saúde, envolvidas com a construção de homens e mulheres cada vez mais autônomos e qualificados para apostarem na produção da vida, como valor de uso inestimável para si e para os outros, em todas as suas formas de expressão e dimensões, é a grande missão do campo da saúde.

Sem dúvida, a humanidade construiu muitos tipos distintos de saberes nesta direção, não sendo privilégio de nenhum, em particular, ser eficaz e efetivo no cumprimento desta missão. São muitas as formas de realizá-la.

Entretanto, independente da conformação tecnológica que o agir em saúde adquirir, deverá responder sempre as mesmas questões-chave: do ponto de vista da ética da vida, o que você produz? você aposta na vida? como?

Se o agir estiver voltado para si mesmo e não para o mundo das necessidades de saúde dos usuários dos serviços de saúde, forma de expressão do que a potência de viver ambiciona, não será um caminho interessante a ser defendido. Se este agir não permitir a clareza de que a vida de cada um, e de todos, é igualmente importante, não poderá contribuir para uma sociedade mais solidária. Terá de contribuir sem titubeio, no seu modo de operar no dia a dia a produção da saúde, com a produção de um imaginário social no qual a vida é um valor em si a ser preservado, sob todas as suas formas de expressão, e que as melhores maneiras disso ser constituído é respeitar e apostar na qualificação da vida dos seres humanos e na evidência de que, pela importância que estes têm em protagonizar novos sentidos para o mundo, eles estão fundamente responsabilizados pela possibilidade de sobrevivência da vida ou da sua destruição, aqui na Terra.

Terá que apontar para outros caminhos que não os que as sociedades capitalísticas, incrivelmente 
instrumentais, construíram para praticar o consumo da vida individual e coletiva. Ou seja, terá que mostrar a compatibilidade entre produzir vida para os humanos, produzindo vida para o mundo como um todo, em um sentido invertido em relação às sociedades atuais.

\section{visualizando possibilidades de gestões democráticas do público}

As sociedades, hoje, têm caminhado para consagrar a imagem de que o privado, sob qualquer forma, é o que vale. $\mathrm{E}$, neste processo, vai-se consolidando como natural que tudo que é público, que é coletivo, é ruim ou pouco interessante. $E$, com isso, os indivíduos e coletivos vão também se convencendo e vivendo de acordo com estas idéias. A tensão público e privado vai pendendo para o individualismo, pela não responsabilização pública dos atos pessoais, pela premissa do aqui e agora, pela ética da não prestação de contas.

A possibilidade de colocar em cheque esta forma de só responder à sua consciência ou, no máximo, no caso da saúde, à sua corporação profissional ou política, é uma idéia-aposta fundamental se o que se deseja é a ação individual e coletiva, no dia a dia da produção da saúde, como maneiras de produzir a defesa da vida.

Perguntar no seu dia a dia: se há clareza dos rumos; se todos procuram conversar sobre suas limitações e potencialidades, sobre seus resultados conquistados; sobre que apostas estão fazendo e como as estão construindo coletivamente; sobre que tipos de privilégios existem nos seus agires e de que modo podem colocar em debate público e processar decisões em torno dos seus modos de atuarem; é um dos movimentos interessantes de serem feitos nos microprocessos pelos coletivos de trabalhadores envolvidos, que não podem esquecer de que devem ambicionar, neste círculo, a conhecer e submeter a uma discussão os processos de outros níveis colocados além do seu terreno do coletivo, em particular aqueles que definem o que são os fundos públicos ou sociais que financiam as ações de saúde e como sua gestão é feita. Quem os governa? De que modo e com que finalidades? A que interesses obedecem? E como determinam suas decisões? Como praticam a democracia em seu âmbito? De que modo são influenciados pelos desejos dos que estão na construção das práticas de saúde, no dia a dia da vida?

A gestão democrática das intenções das políticas, bem como do operar o cotidiano dos processos produtivos em saúde, deve estar em interrogação o tempo todo junto aos coletivos em círculos de tensões enriquecedoras.

\section{enfrentando a revolução tecnológica do setor, centrada no capital, com projetos centrados na vida} Para inverter a lógica da globalização capitalística que vem inventando uma nova lógica produtiva para o setor saúde, centrada no capital, pela da cidadania solidária e da defesa radical da vida individual e coletiva, contrapondo-se aos projetos neoliberais do grande capital e dos médicos empresários, deve-se interrogar a que intenções do agir tecnológico, obedece. Operase os saberes tecnológicos - nas suas expressões duras (equipamentos), leves (relacionais) e leve-duras (clínica, epidemiologia) - em função da lógica centrada em procedimentos, na lógica lucrativa do capital? Ou na lógica de satisfazer as necesidades dos usuários?

Uma forma de os coletivos interrogarem estes possíveis sentidos, em qualquer nível, no da política, da organização ou da produção do cuidado, é tomando como referencial a complexa forma de expressão do mundo das necessidades dos usuários, individuais ou coletivos. Cabe, em última instância, perguntar de que modo e com que capacidade o agir tecnológico contribui para satisfazer as necessidades de boas condições de vida, de se viver em processos sociais de inclusão, de ser alguém singular, sujeito de direito e cidadão, ser nominal; de que modo contribui para garantir $o$ acesso a todas as tecnologias que melhorem e prolonguem a vida, de ser acolhido e ter vínculo com um profissional ou equipe (sujeitos em relação), poder acessar e ser recebido e bem acolhido em qualquer serviço de saúde que necessitar, tendo sempre uma referência de responsabilização pelo seu atendimento dentro do sistema; de que modo produz autonomia e autocuidado na escolha do modo de "andar a vida" (construção do sujeito), sujeito do saber e do fazer, em produção, que irá a cada momento "operar" seu próprio modo de andar na vida? Submetendo, assim, seu modelo tecno-assistencial a um julgamento centrado no usuário, o lugar legítimo a definir o sentido e as intencionalidades do agir em saúde.

a saúde é um bem público e como tal deve ser tratada pelas políticas: socializar o estado e dar novos sentidos sociais para o privado

A disputa efetiva que é travada no mundo entre a saúde como bem público, direito de todos e problema

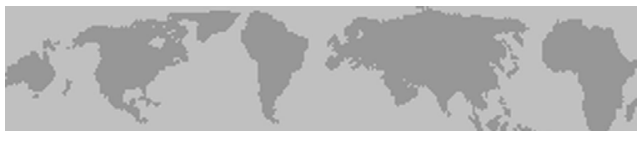


de toda a sociedade, ou de mercado trocável por qualquer moeda, é uma tensão central em todos os lugares. Porém, deve-se reconhecer que a forma privada de prestação de serviços de saúde é um dado da realidade não tão fácil de ser negado, tornando-se questão-chave a possibilidade de equacionar as distintas modalidades de produção de saúde sobre sua natureza pública e subordinar qualquer uma destas modalidades à lógica última deste interesse. Apostar que mesmo a produção privada de serviços de saúde pode almejar intenções de comercialização, produzindo saúde e respeitando-a como bem público.

Nesta direção, regular o privado tem sido um ganho no mundo que trata da ótica do direito universal e eqüânime. $\mathrm{O}$ caminho que não torna incompatível a produção privada de serviços de saúde, ou similares, com a própria produção da vida e com o eixo ordenador do agir em saúde, em função da construção de uma vida mais autônoma e mais qualificada, para cada um e para todos, é um tremendo desafio, mas não impossível. Em particular, naquelas sociedades em que a vida é vista por uma lógica muito instrumental e nas quais só a de alguns é valorizada como um valor de uso inestimável.

A produção privada de serviços de saúde, ou similares, deve ser enfrentada sob o princípio realista de que as sociedades humanas terão que equacionar a responsabilização social de qualquer um que esteja operando neste campo de práticas, inclusive os próprios serviços estatais, que por si só não são públicos, nos sentidos que vimos tratando neste texto, e, por isso, uma das grandes aprendizagens é a de que só uma grande capacidade de regular e impor certos percursos para alguns processos produtivos é que os têm tornado lugares dos interesses mais públicos, dos interesses de todos.

Trabalhar com o lema: quem quiser operar a produção de serviços de saúde de modo privado (visando um bem de mercado), que opere, mas que o faça produzindo saúde (governado pela produção do valor de uso saúde), conforme o que o conjunto dos interesses sociais, pautados pela defesa radical da vida individual e coletiva, impõe.

Deste modo, algumas das questões que podem ser colocadas para os gestores das políticas governamentais em saúde, são: suas atividades de regulação e controle sobre o conjunto dos produtores de práticas de saúde, conformam o quê?

Direcionalidades para o agir tecnológico que o impliquem com o mundo das necessidades dos usuários, ou se ordenam pelos interesses econômicos e/ou corporativos dos empresários, gestores e trabalhadores, do setor, em si? Para isso, favorecem a produção de saúde ou a sacrificam pelos interesses particulares dos empresários e dos trabalhadores do setor?

Creio que os únicos interesses privados do setor saúde que devem ser respeitados, acima de tudo, são os dos usuários, reais expressões corporificadas do que são as necessidades de saúde.

\section{Enfim}

Procurei, neste texto curto, dar conta de muitas questões, o que pode, muitas vezes, ter sacrificado a clareza, mas há uma que é central: o Fórum Social Mundial não deve ser visto como uma dada corrente política e que adota um projeto programático fechado. Deve, sim, representar o encontro de multiplicidades que apostam que sujeitos sujeitados podem emergir como sujeitos autônomos produtores de novos sentidos para o viver, mais efetivos nos seus compromissos com a vida como o valor de uso máximo a ser preservado; apostar que processos interrogadores sejam dispositivos eficazes para contribuir para este tipo de processo; ambicionar o instigamento de coletivos e indivíduos, sobre questões que possam colocá-los em tensões produtivas de novas subjetividades, em torno das problemáticas que podem afetar a possibilidade e a capacidade de se produzir saúde ou não. Entretanto, provocar que isso se transforme em situações de intervenções sobre a realidade, em uma busca militante por um novo sentido para a vida, comprometido com a cumplicidade por todas as suas formas de expressão: humanas, sociais e ecológicas, é responsabilidade de cada um e de cada coletivo, que por suas ações podem produzir ou desproduzir mais vidas.

Aposta-se aqui, que coletivos e indivíduos em tensões criativas em torno de suas responsabilidades por isso, tornam-se mais sujeitos de seus destinos, mais sujeitos de uma ética global da vida, mais comprometidos com a liberdade e a igualdade.
PALAVRAS-CHAVE: Ética; ação intersetorial; política de saúde.
KEY WORDS: Ethics; intersectorial action; healthcare policy.
PALABRAS CLAVE: Ética; acción intersectorial; política de salud. 